\title{
Airborne dissemination of Burkholderia (Pseudomonas) cepacia from adult patients with cystic fibrosis
}

\author{
H Humphreys, D Peckham, P Patel, A Knox
}

\begin{abstract}
Background - Burkholderia (Pseudomonas) cepacia is an increasingly important pathogen in patients with cystic fibrosis but it is unclear how it spreads from patient to patient. A study was undertaken to determine whether $B$ cepacia could be recovered from room air occupied by colonised adult patients with cystic fibrosis.

Methods - Air samples were obtained consecutively from an enclosed room or isolation cubicle before, during, and after occupation by six patients on nine occasions using a surface air sampler incorporating contact plates with selective medium. Settle plates were also used and sputum from five patients was cultured.

Results - B cepacia was recovered from room air during occupation by five of six patients, the number of bacteria ranging from 1 to $158 \mathrm{cfu} / \mathrm{m}^{3}$ (mean $32 \mathrm{cfu} / \mathrm{m}^{3}$ ). The number of bacteria isolated was greater when patients were coughing. $B$ cepacia persisted in room air on four occasions after the patient left the room, on one occasion for up to $\mathbf{4 5}$ minutes.

Conclusions - The isolation of $B$ cepacia from the air of rooms occupied by colonised patients suggests that dissemination might occur by aerosol as well as by direct physical contact with patients or contaminated environmental sites.
\end{abstract}

Department of Microbiology/Public Health Laboratory, University Hospital, Nottingham NG7 2UH H Humphreys

Department of Respiratory Medicine, City Hospital, Nottingham

D Peckham

A Knox

Laboratory of Hospital Infection, Central Public Health

Laboratory, London

P Patel

Reprint requests to: Dr H Humphreys.

Received 15 October 1993 Returned to authors 29 March 1994

Revised version received 4 May 1994

Accepted for publication 5 September 1994
(Thorax 1994;49:1157-1159)

There is increasing interest in Burkholderia (Pseudomonas) cepacia ${ }^{12}$ as a cause of infection in patients with cystic fibrosis in North America and Europe. ${ }^{3}$ Acquisition by patients with cystic fibrosis may follow three clinical courses: long term colonisation without deterioration in pulmonary function, chronic infection, or acute fulminating disease with rapidly deteriorating lung function and death within weeks. ${ }^{4}$ Risk factors for acquisition include severe pulmonary disease, recent admission to hospital, aerosol therapy, and a $B$ cepacia infected sibling. ${ }^{34}$ The pathogenicity of this organism in man is poorly understood and many doubt its ability to cause disease. Pre-existing lung damage and the effects of other pathogens may enhance its pathogenic potential, ${ }^{5}$ although in a recent study of 13 patients colonised by $B$ cepacia only eight (62\%) were also colonised with Pseudomonas aeruginosa. ${ }^{6}$
There is considerable anxiety amongst patients, their families, and physicians that person-to-person transmission may occur. Patients may contaminate the immediate environment resulting in indirect transmission. ${ }^{7}$ Ribotyping strongly implicates person-to-person spread, ${ }^{8}$ and the question arises whether positive patients should be segregated from other patients. We report the airborne dissemination of $B$ cepacia from colonised patients with cystic fibrosis.

\section{Methods}

PATIENTS

Colonisation of patients with cystic fibrosis in Nottingham by $B$ cepacia was first confirmed in November 1991 and now involves one third (16/48) of adult patients. Six colonised adult patients were studied (three on two occasions). Patients were chosen on the basis of availability and willingness to participate, but were representative of all colonised patients. The subjects were also persistently colonised with $P s$ aeruginosa. There were four men and two women, and the mean age was $22 \cdot 7$ years (range 20-27). All had progressive lung deterioration before isolation of $B$ cepacia with a forced expiratory volume in one second $\left(\mathrm{FEV}_{1}\right)$ of $36.3 \%$ predicted and a mean forced vital capacity (FVC) of $52 \cdot 7 \%$. Two of the patients were awaiting lung transplantation while four were on one or more intravenous antibiotics and none was receiving nebulised antibiotics.

\section{MICROBIOLOGY}

\section{Sputum culture}

Sputum from five of the six patients was inoculated on to $B$ cepacia selective medium (MAST, UK) incorporating ticarcillin and polymyxin $B$ to achieve a final concentration of $100 \mathrm{mg} / \mathrm{l}$ and 300000 units/l, respectively. Agar plates were incubated for 40 hours at $37^{\circ} \mathrm{C}$. Isolates were confirmed as $B$ cepacia in conjunction with the Division of Hospital Infection, Central Public Health Laboratory if they were resistant to polymyxin $\mathrm{B}$, oxidative in Hugh and Leifson's medium, produced cytochrome oxidase, did not produce arginine dihydrolase, and grew on Simmons' citrate medium. ${ }^{9}$

\section{Environmental sampling}

A surface air system (SAS) air sampler (Cherwell Laboratories, UK)) positioned $100 \mathrm{~cm}$ 
Air counts (colony forming units $/ \mathrm{m}^{3}$ ) of Burkholderia cepacia

\begin{tabular}{llll}
\hline Patient no. & Counts (room occupied)* & Counts (room empty) & Settle plates \\
\hline 1 & (1) $1-7$ & (1) Positive at $0,15 \mathrm{~min}$ & (1) Negative \\
2 & (2) $1-2$ & (2) All negative & (2) Negative \\
3 & $2-3$ & All negative & Negative \\
4 & All negative & All negative & Negative \\
5 & $1-3$ & All negative & Negative \\
6 & (1) $23-97$ & (1) Positive at 0,15 and $30 \mathrm{~min}$ & (1) Positive \\
6 & (2) $27-121$ & (2) Positive at $0,15,30$ and 45 min & (2) Not done \\
& (1) $105-158$ & (1) Positive at 0 min & (1) Negative \\
& (2) $2-7$ & (2) All negative & (2) Positive \\
\hline
\end{tabular}

* Range during coughing and whilst at rest.

from the patient was used to sample 9001 of air over a five minute period before and during occupation of an enclosed room $(2.2 \mathrm{~m} \times 3 \mathrm{~m} \times 2.5 \mathrm{~m}$ or an isolation cubicle $(3.3 \mathrm{~m} \times 3 \mathrm{~m} \times 2.7 \mathrm{~m})$ by patients while coughing and while at rest. Air samples were taken at 15 minute intervals for one hour after the patient had vacated the room and also 18 hours later. There was at least one week between sampling of room air occupied by different patients. The SAS sampler aspirates air by a fan at a fixed speed $(180 \mathrm{l} / \mathrm{min})$ to a maximum of 9001 over five minutes. Air was directed on to the agar surface of a contact plate containing $B$ cepacia selective medium as described above. Contact plates were incubated in air at $30^{\circ} \mathrm{C}$ for up to seven days and the number of colonies counted and corrected for the coincidence of two or more colony forming units (cfu) passing through the same hole. ${ }^{10}$ The number of bacteria isolated was expressed as $\mathrm{cfu} / \mathrm{m}^{3}$ of air.

Settle plates, also incorporating $B$ cepacia medium, were placed for 18 hours in the immediate vicinity of patients on all but one occasion.

\section{Results}

$B$ cepacia was recovered from room air during occupation by five of the six patients (table). All samples taken before occupation were negative. Sputum was unavailable for culture from patient 3 at the time of the study but subsequent samples have been positive. The amount of $B$ cepacia recovered from positive room air ranged from 1 to $158 \mathrm{cfu} / \mathrm{m}^{3}$ with a mean of $32 \mathrm{cfu} /$ $\mathrm{m}^{3}$. Twenty three of 25 air samples obtained while patients were coughing and eight of 12 taken when not coughing were positive. The mean count during coughing was $40 \mathrm{cfu} / \mathrm{m}^{3}$ compared with $15 \mathrm{cfu} / \mathrm{m}^{3}$ of air samples at rest.

Following exit of the patient from the room, $B$ cepacia was recovered on four occasions (three patients, table). In two patients samples were positive at 15 and/or 30 minutes. Counts ranged from 3 to $53 \mathrm{cfu} / \mathrm{m}^{3}$ of air. Air counts taken from the enclosed room occupied by patient 5 (second occasion) ranged from 27 to $121 \mathrm{cfu} / \mathrm{m}^{3}$ and a sample was also positive 45 minutes after departure. Settle plates were positive on two occasions (patients 5 and 6 ).

\section{Discussion}

$B$ cepacia was present in the air of a closed room or isolation cubicle during and following occupation by patients with cystic fibrosis and persisted for up to 45 minutes afterwards. All air samples were negative before occupation and it is assumed that airborne bacteria originated from the patients. This suggests that airborne contamination by $B$ cepacia is possible and may be a mode of transmission in addition to person-to-person spread by physical contact with colonised patients or contaminated surfaces.

Some of our patients were receiving antibiotics for the treatment of Ps aeruginosa infection and the impact of this on dissemination is unclear because $B$ cepacia in Nottingham is resistant to gentamicin, tobramycin, azlocillin, aztreonam, imipenem, and ciprofloxacin. Combinations of antimicrobial agents may result in lower counts of $B$ cepacia because of synergistic activity. Alternatively, antibiotics may have selected for $B$ cepacia and assisted in dissemination by reducing other respiratory flora. Quantitative sputum cultures, which were not carried out in this study, might clarify the effect of antibiotic treatment.

The importance of air in the transmission of infection is well recognised but the sampling of hospital air for microbiological purposes is only indicated as part of operating theatre commissioning during an outbreak of infection or for research. Accurate methods include slit air samplers or the SAS sampler which are convenient and acceptable for most purposes. ${ }^{1011}$ Settle plates are a crude, if cheap, method and may not correlate with results from an SAS sampler as was the case for patient 6 .

A retrospective case-control study has implicated the use of nebuliser or humidifier therapy in nosocomial acquisition as $B$ cepacia was isolated from nebuliser reservoirs although air samples were negative. ${ }^{12}$ The spread of $B \mathrm{ce}$ pacia amongst patients with cystic fibrosis attending two centres in the UK was documented using bacteriocin and molecular typing. ${ }^{6}$ The organism was isolated from the hands of three patients and disposable spirometry equipment. ${ }^{6}$ The authors of both studies recommend patient segregation for hospital inpatients and outpatients. The failure to isolate $B$ cepacia from air samples in these studies may be due to differences between the patients and the circumstances and frequency of monitoring air, and the technique used. Slit samplers as used in these two studies operate at an air flow of $30 \mathrm{l} / \mathrm{min}$ whereas the SAS system can sample at $180 \mathrm{l} / \mathrm{min}$.

$B$ cepacia has been isolated from equipment, shower drains, vase water, and plant soil, ${ }^{34}$ which probably reflects contamination from heavily colonised patients. The survival of this organism, especially in moist environments, may also be a factor, and transmission in saliva 
via direct contact (kissing) or shared vessels or eating utensils is possible. The involvement of many adult cystic fibrosis patients in self-help and social groups means that frequent and regular meetings occur and close, even intimate, contact may arise. Consequently, patient-to-patient transmission via direct contact, contact with contaminated environmental sources, or possibly by the airborne route must be considered here as well as in hospital.

Physical separation in hospital of patients colonised with $B$ cepacia in their sputum has led to a decrease in the incidence of this organism in patients with cystic fibrosis. ${ }^{13}$ Burkholderia cepacia positive patients should avoid kissing and other intimate contact with non-colonised patients. ${ }^{14}$ We have segregated patients since May 1992, but guidelines to minimise the transmission of $B$ cepacia must take account of social and emotional factors and avoid making patients feel like outcasts. ${ }^{15}$ The findings that $B$ cepacia may contaminate room air suggests that segregation whilst in hospital should be continued where possible.

The authors wish to thank Sister $S$ Wynne, Adult Cystic Fibrosis Unit at the City Hospital, Nottingham, and $\mathrm{Ms} \mathrm{J}$ Hyde and $\mathrm{Mr}$ M Baker, Public Health Laboratory, Nottingham for their help during the conduct of this study. They also wish to acknowledge the assistance of Dr T L Pitt, Laboratory of Hospital Infection, the assistance of Dr T L Pitt, Laboratory of Hospital Infection,
Central Public Health Laboratory for valuable discussions during the preparation of this manuscript. DP and PP are supported by the Cystic Fibrosis Trust.
1 Yabuuchi E, Kosako Y, Oyaizu H, Yano I, Hotta H, Hashimoto Y, et al. Proposal of Burkholderia gen. nov. and transfer of seven species of the genus Pseudomonas homtransfer of seven species of the genus Pseudomonas hom-
ology Group II to the new genus, with the type species ology Group II to the new genus, with the type species
Burkholderia cepacia (Palleroni and Holmes 1981) comb. nov. Microbiol Immunol 1992;36:1251-75.

2 Validation of the publication of new names and new combinations previously effectively published outside the IJSB. List No 45. Int $\mathcal{F}$ Syst Bacteriol 1993;43:398-9.

3 Tablan OC, Martone WJ, Jarvis WR. The epidemiology of Pseudomonas cepacia in patients with cystic fibrosis. Eur $f$ Epidemiol 1987;3:336-42.

4 Gilligan PH. Microbiology of airway disease in patients with cystic fibrosis. Clin Microbiol Rev 1991;4:35-51.

5 Gladman G, Conner PJ, Williams RF, David TJ. Controlled study of Pseudomonas cepacia and Pseudomonas maltophilia study of Pseudomonas cepacia and Pseudomonas matc

6. Govan JRW, Brown PH, Maddison J, ei al. Evidence for transmission of Pseudomonas cepacia by social contact in cystic fibrosis. Lancet 1993;342:15-9.

7 Nelson JW, Doherty CJ, Brown PH, Greening AP, Kaufmann ME, Govan JRW. Pseudomonas cepacia in inpatients with cystic fibrosis. Lancet 1991;338:1525.

8 Lipuma JJ, Dasen SE, Nielson DW, Stern RC, Stull TL. Person-to-person transmission of Pseudomonas cepacia between patients with cystic fibrosis. Lancet 1990;336:1094-6.

9 Barrow GI, Feltham RKA, eds. Cowan and Steel's manual for the identification of medical bacteria. 3rd edn. Cambridge: Cambridge University Press, 1993:110.

10 Lach V. Performance of the surface air system air samplers. $\Im$ Hosp Infect 1985;6:102-7.

11 Humphreys H. Microbes in the air - when to count! (The role of air sampling in hospitals). $f$ Med Microbiol 1992, 37:81-2.

12 Burdge DR, Nakielna EM, Noble MA. Case-control and vector studies of nosocomial acquisition of Pseudomona cepacia in adult patients with cystic fibrosis. Infect Control Hosp Epidemiol 1993;14:127-30.

13 Thomassen MJ, Demko CA, Doershuk CF, Stern RC, Klinger JD. Pseudomonas cepacia: decrease in colonization in patients with cystic fibrosis. Am Rev Respir Dis 1985 134:669-71.

14 Editorial. Pseudomonas cepacia - more than a harmless commensal? Lancet 1992;339:1385-6.

15 Walters S, Smith EG. Pseudomonas cepacia in cystic fibrosis: transmissibility and its implications. Lancet 1993;342:3-4. 